\title{
A Novel Tin-Doped Titanium Oxide Nanocomposite for Efficient Photo-anodic Water Splitting
}

\author{
Manzar Sohail $^{a}$, Nadeem Baigb, Muhammad Sherc, Rabia Jamila, Muhammad Altafe, \\ Sultan Akhtar ${ }^{d}$, Muhammad Sharif ${ }^{*}$ \\ aDepartment of Chemistry, School of Natural Sciences, National University of Sciences and \\ Technology, Islamabad 44000, Pakistan.

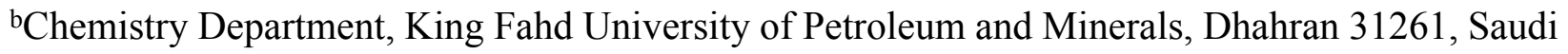 \\ Arabia. \\ 'Department of Chemistry, Allama Iqbal Open University, Islamabad, Pakistan. \\ ${ }^{\mathrm{d} E l e c t r o n}$ Microscopy Unit, Institute for Research and Medical Consultations, Imam Abdulrahman \\ Bin Faisal University, Dammam 31441, Saudi Arabia. \\ eDepartment of Chemistry, Government College University, Lahore, Pakistan.
}

\section{*Corresponding author:}

Manzar Sohail

Department of Chemistry, School of Natural Sciences, National University of Science and Technology, Islamabad 44000, Pakistan E.mail: Manzar.sohail@,sns.nust.edu.pk; Tel. +92-519058-5596 


\section{Supplementary Information}

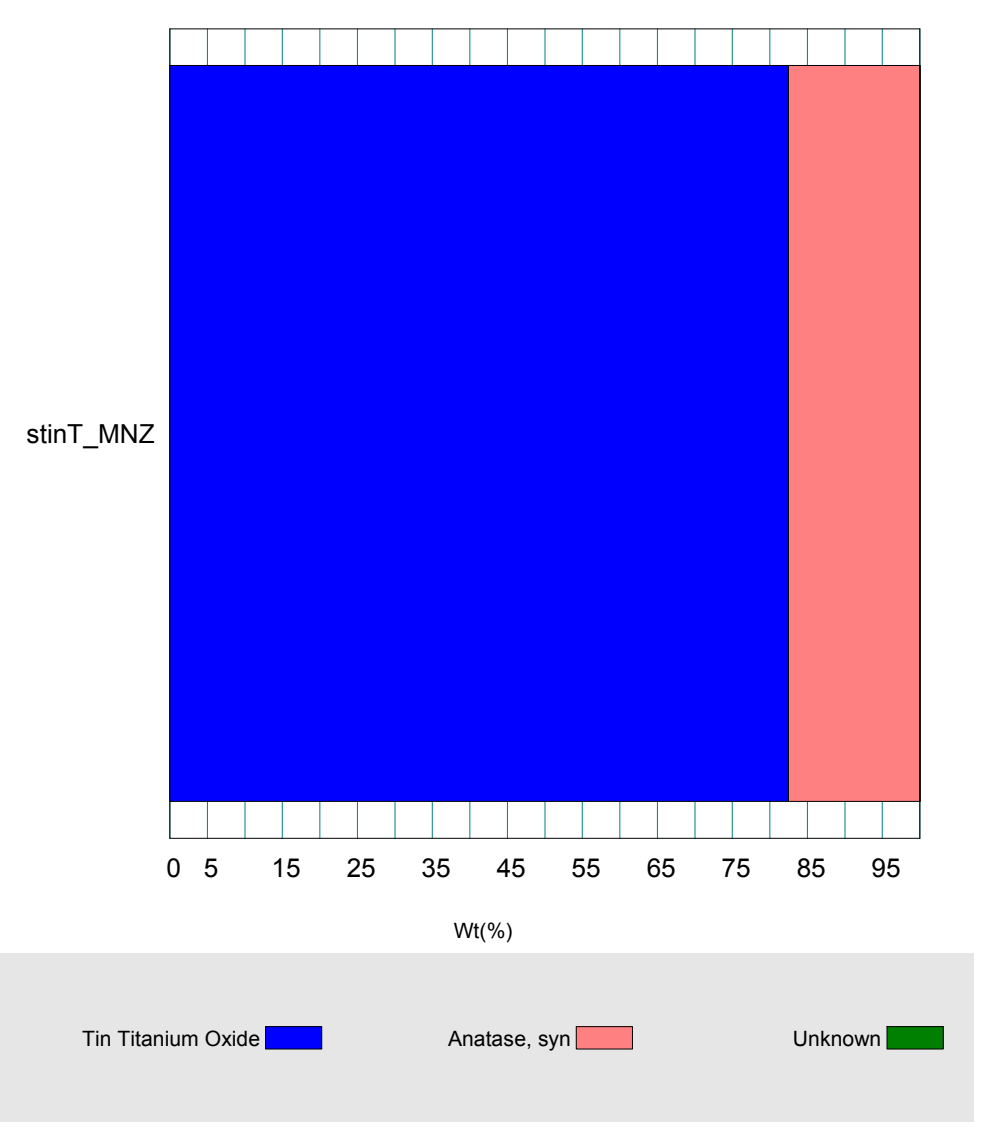

Figure S1. Relative intensity ratio (RIR) analysis from pXRD, of the $\mathrm{Sn}_{0.39} \mathrm{Ti}_{0.61} \mathrm{O}_{2}$. $\mathrm{TiO}_{2}$ nanocomposite (Tin Titanium Oxide $82.5 \%, \mathrm{TiO}_{2}$ (Anatase $17.5 \%$ ). 


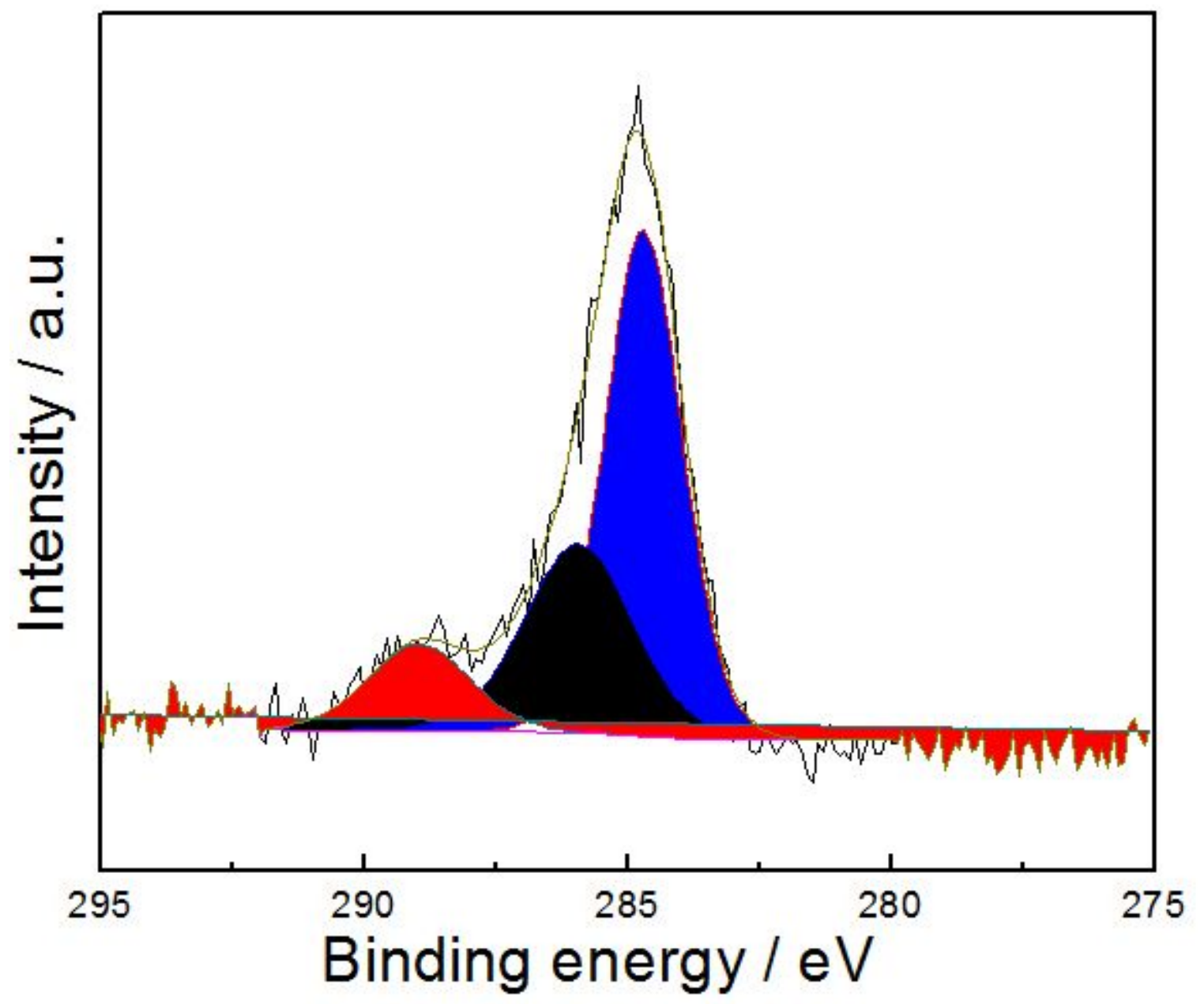

Figure S2. C1s high resolution XPS spectrum 


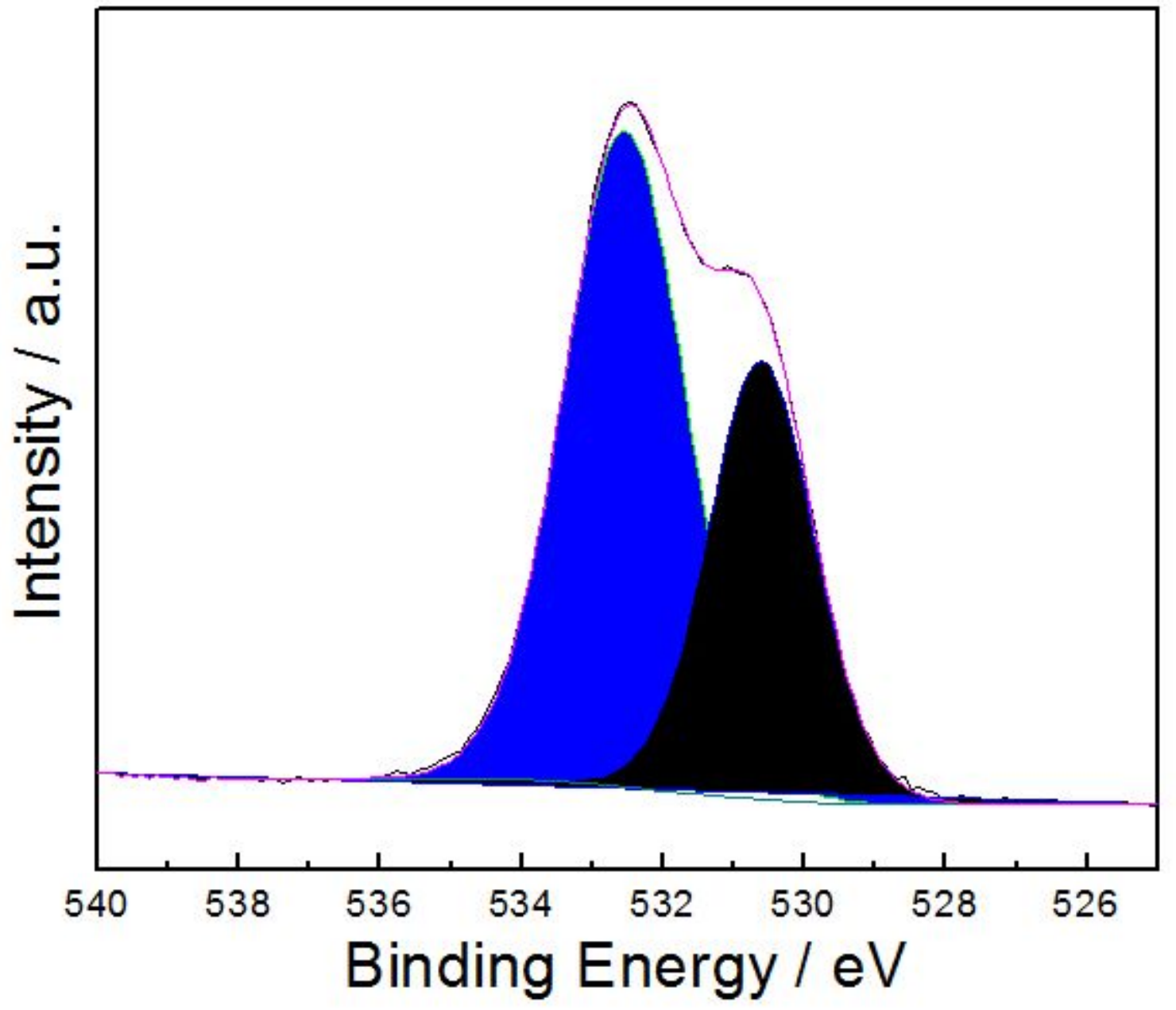

Figure S3. O1s high resolution XPS spectrum 

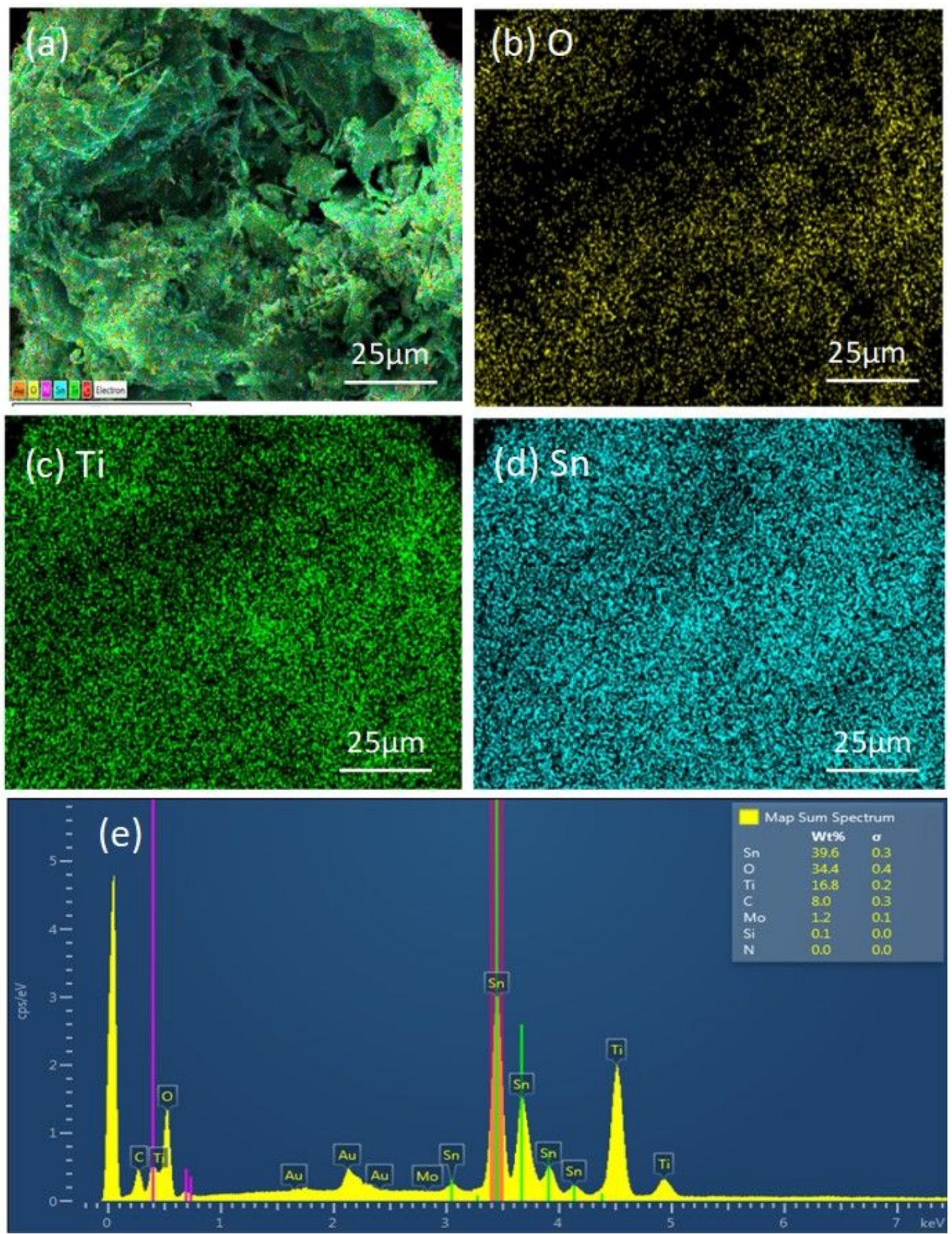

Figure S4. EDX mapping images and EDS spectrum of the $\mathrm{Sn}_{0.39} \mathrm{Ti}_{0.61} \mathrm{O}_{2} \cdot \mathrm{TiO}_{2}$ composite. EDX mapping of the $\mathrm{SnTiO}_{2}$ photocatalyst demonstrates the uniform distribution of its elements. EDX mapping analysis of (b) Oxygen, (c) Titanium and (d) Tin. EDX spectrum of the synthesized $\mathrm{Sn}_{0.39} \mathrm{Ti}_{0.61} \mathrm{O}_{2} \cdot \mathrm{TiO}_{2}$ photocatalyst showing the existence of different components, $\mathrm{Ti}, \mathrm{Sn}$, and $\mathrm{O}$. The Au peak is appeared due to the gold coating of the specimen. 


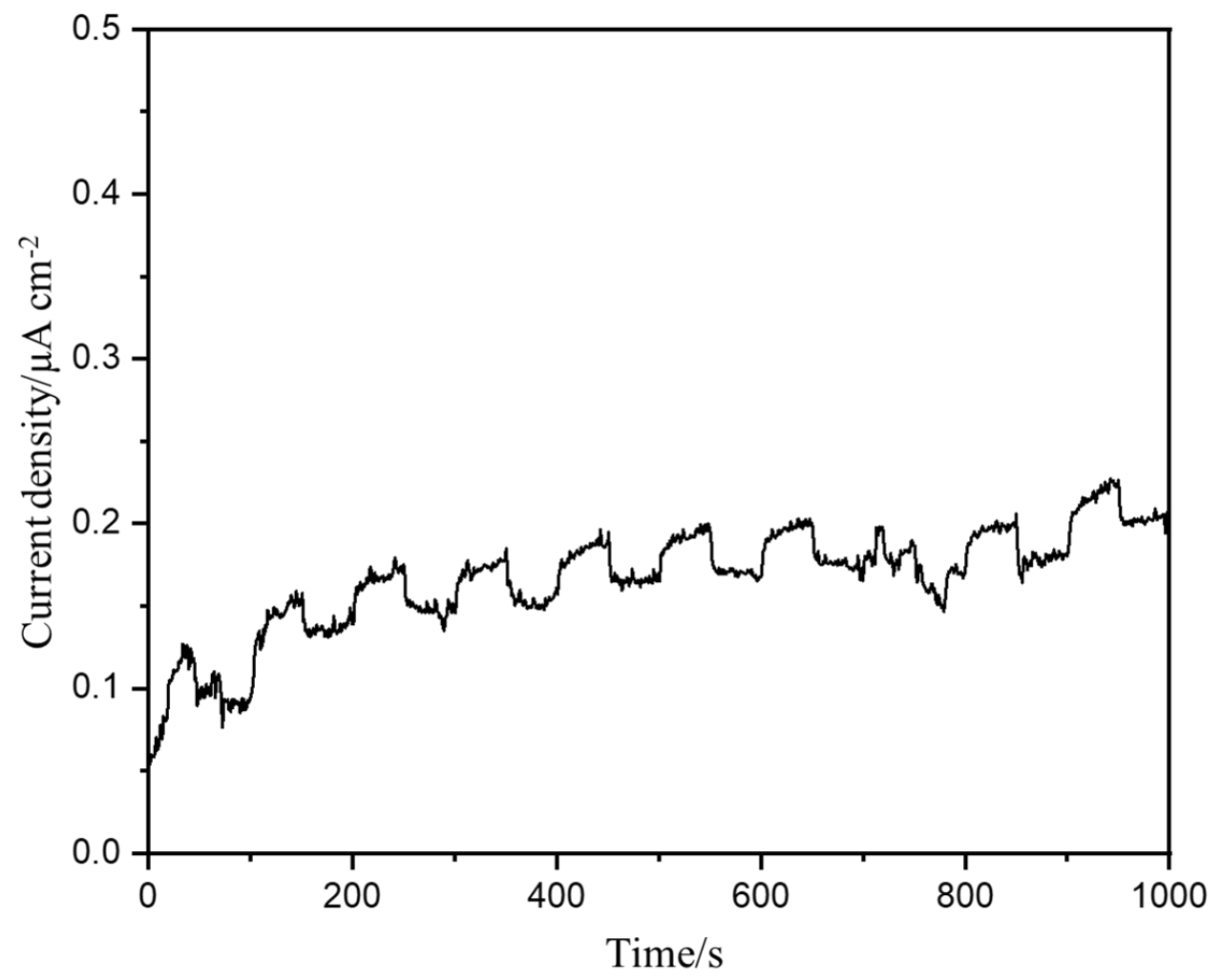

Figure S5 Chronoamperometery in light chopping mode of $\mathrm{TiO}_{2}$ anatase/ FTO response for OER reaction under dark and light. 


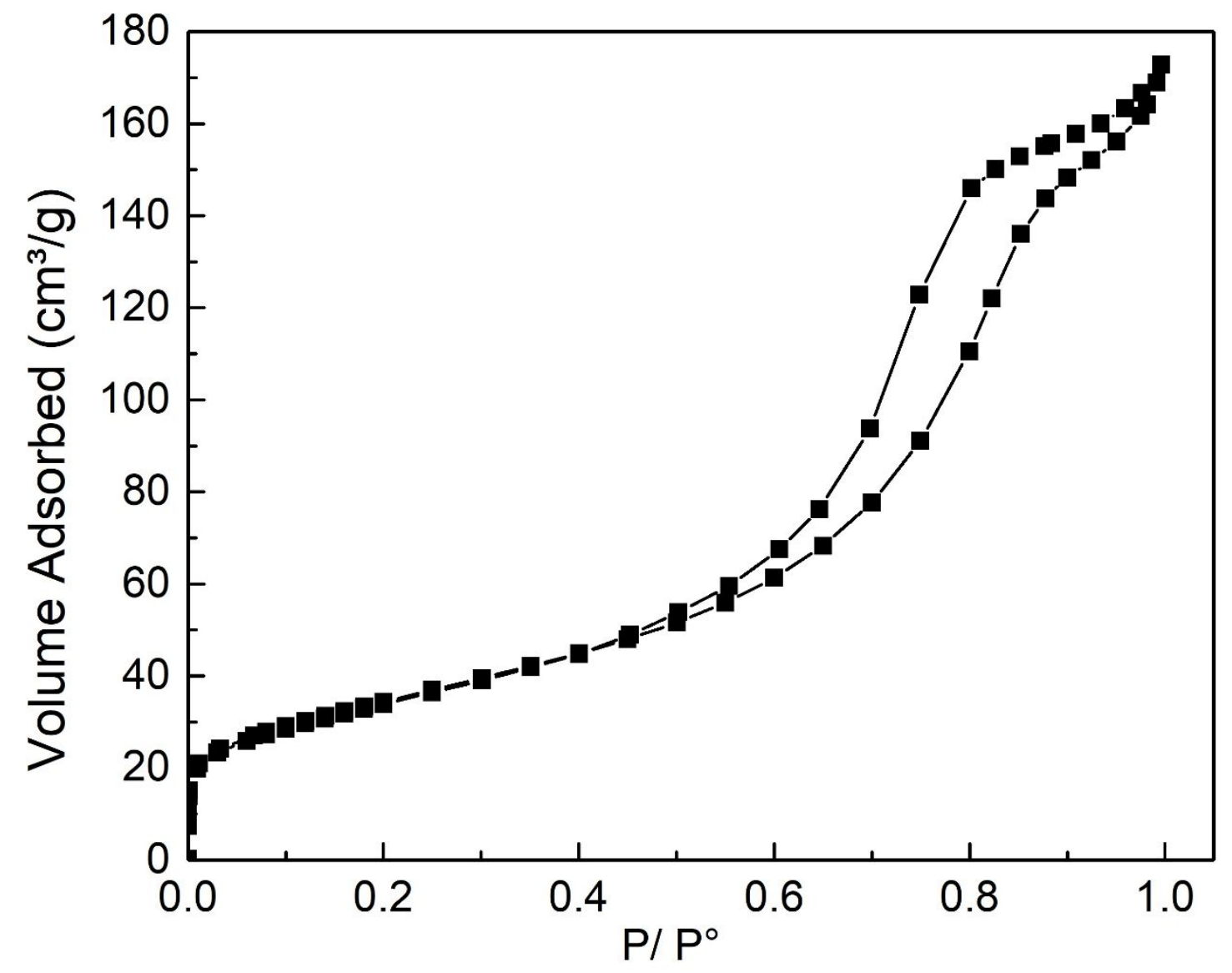

Figure S6. BET adsorption-desorption isotherm graph for $\mathrm{Sn}_{0.39} \mathrm{Ti}_{0.61} \mathrm{O}_{2} \cdot \mathrm{TiO}_{2}$ 